\title{
Current Status of Indigenous Chicken Production in Moyamba District, Sierra Leone.
}

\author{
Abdulai Mahmood Conteh ${ }^{1 *}$, Abdul Rahman Sesay ${ }^{2}$ \\ School of Agriculture, Department of Animal Science, Main Campus, Njala University.
}

*Corresponding Author: Abdulai Mahmood Conteh, School of Agriculture, Department of Animal Science, Main Campus, Njala University.

\begin{abstract}
Indigenous Chicken production is a common practice in Sierra Leone that strengthen the livelihoods, economic and socio-cultural wellbeing of many rural farmers. Regardless of their significant roles, some challenges undercut the productivity of these chickens if key measures are not taken. It is against this backdrop the study was conducted to investigate the current status of Indigenous Chicken Production in Moyamba District, Sierra Leone. Data was gathered using semi-structured questionnaires, personal observation, and discussions from 222 randomly selected participants in six communities. The result revealed that household consumption, socio-cultural practices, income earning and maintaining breeding stock, were identified as the main reason for keeping indigenous chickens. Chickens were mainly owned and managed by women (70.9\%) assisted by children under the traditional management system. Major constraints including diseases/parasites, high mortality, poor conventional treatment, lack of information, poor market, predators attack, and inadequate feeding were reported. The main disease reported was Newcastle disease (ND) while hawk and lice were serious predator and ectoparasite in the study areas respectively. $81.0 \%$ of the respondents used traditional medicines to treat sick birds, $2.9 \%$ admitted to basic veterinary services while $16.1 \%$ offered no treatment services. Good management practices including biosecurity, and vaccination was not adhered to. 59.5\% of the farmers shared their dwelling houses with their chickens, 9.5\% built separate chicken houses while $31.1 \%$ did not provide shelter. There is a need to strengthen animal healthcare, marketing opportunities as well as extension and research services in the district.
\end{abstract}

Keywords: Constraints, diseases, free-range, livelihood, management, marketing, mortality, Predators.

\section{INTRODUCTION}

Indigenous chicken production (ICP) is a significant component of livestock production in many countries. Approximately $80 \%$ of the world poultry populations for which most of them are indigenous breeds are managed at the traditional free-range system $(1,2)$. Albeit this system of poultry production has received little attention, it still performs key functions such as supporting livelihood and enhancing economic empowerment. Household consumption, poverty reduction, promoting gender equality and socio-cultural practices, scaling down malnutrition, creating employment and providing extra cash are well documented as contributions of Indigenous Chickens (ICs) to rural and peri-urban households in developing countries $(3,4,5)$. However, disease outbreaks, predation, poor veterinary and extension services, weak institutional support, inadequate housing and lack of a wellstructured market facility were, the major constraints identified $(6,7)$. In light of these disadvantages, ICP is a preferable system as a cost-effective way in which to rear poultry in rural and peri-urban areas. There is growing evidence supporting that poultry that is reared in the free-range system could manage and survive in extremely hostile environments, in addition to their tolerance against some endemic diseases and perform better under inadequate and fewer quality feeds $(8,2)$.

In Sierra Leone, agriculture is the mainstay and the largest sector of the economy employing approximately $70 \%$ of the population with a national GDP of 50\% $(9,10)$. Among the different livestock species reared in the country, poultry is the most populated $(4,316,349)$ and it is predominantly owned and managed by women (10). Though poultry is the largest livestock rear in Sierra Leone, its calorie's contribution has been reported low $(0.63 \%)$ compared to other livestock [5.24\%) (11)]. In Sierra Leone, more than two-thirds of the national population rear livestock including poultry with $90 \%$ accounting for the backyard rural poultry. Traditional management 
characterized by high mortality, improper breed selection, poor bio-security, diseases, predators, inadequate feeding and housing facilities, is the main production system. Since there are good reasons to believe that indigenous poultry farming is of immense contribution to local livelihood and other spheres of human development, this work explores the current status of indigenous chicken production at the free-range or extensive level in selected villages within the Moyamba District. The specific objectives were to investigate (1) the management practices of ICP (2) the important of ICP to livelihood in the study area and, (3) the constraints faced by farmers in rural areas. Although this study is not directly aimed at the national level, the result obtained in this pilot study is relevant to discussions about the need for evidence-based intervention of concerned stakeholders to support indigenous poultry farming.

\section{METHODOLOGY}

\subsection{Description of the Study Area}

Moyamba District is the largest district in the southern region of Sierra Leone. Its demographic and geopolitical information has been described in a recent study (12). Agriculture, mining, fishing, and business are the main livelihood options in the district, and they are a reflection of the socio-economic characteristics of the local population. The district is notorious for its various animal species but is mostly reared under the free-range system. Moyamba district has the largest number of poultry populations for the southern region which is the second-largest chicken populated district in the country (10). Although the 11 years brutal civil conflict in Sierra Leone affected all facets of society (agriculture, economy, and education), ICP in the District remained unaffected.

\subsection{Study Design and Data Collection}

Six villages (approximately 4-8 Km apart) were randomly selected to obtain information on ICP within the district. The selection criteria were based on a large number of ICs per village, district, management type. This information was obtained through poultry traders, district livestock workers and public transport providers who routinely plied villages in the district. 37 household heads were targeted per village, accounting for 222 consented household heads, who were randomly selected as respondents. Data were collected between October and December 2018 and were obtained from two complementary sources. Quantitative data were obtained by administering semi-structured questionnaires whereas qualitative data through personal observations, desk research, and discussions.

\subsection{Data Analysis}

Data gathered were analyzed by using Statistical Package for Social Scientist (SPSS) version 23.0. Information obtained was presented in frequencies and percentages through tables and charts. Personal discussions and observations were put into a narrative context for the detailed presentation of findings.

\section{RESUlT AND DISCUSSION}

Table1. Socio-economic characteristics of the respondents

\begin{tabular}{|l|l|l|}
\hline Respondents' gender & Frequency & Percentage \\
\hline Male & 89 & 29.1 \\
\hline Female & 217 & 70.9 \\
\hline Educational level & \multicolumn{2}{|l|}{} \\
\hline Informal & 193 & 63.1 \\
\hline Primary & 67 & 21.9 \\
\hline Secondary & 33 & 10.8 \\
\hline Tertiary & 13 & 4.2 \\
\hline Respondents' category & \multicolumn{2}{|l|}{} \\
\hline Children & 55 & 18 \\
\hline Youth & 201 & 65.7 \\
\hline Old & 50 & 16.3 \\
\hline Number per household & \multicolumn{2}{|l|}{} \\
\hline One-four & 170 & 55.6 \\
\hline Five-eight & 109 & 35.6 \\
\hline Nigh and above & 27 & 8.8 \\
\hline Marital status & \multicolumn{2}{|l}{} \\
\hline
\end{tabular}


Current Status of Indigenous Chicken Production in Moyamba District, Sierra Leone.

\begin{tabular}{|l|l|l|}
\hline Single & 71 & 23.2 \\
\hline Married & 196 & 64.1 \\
\hline Widow/divorce & 39 & 12.7 \\
\hline Major occupation & \multicolumn{2}{|l|}{} \\
\hline Farming & 217 & 70.9 \\
\hline Business & 42 & 13.7 \\
\hline Formal employment & 19 & 6.2 \\
\hline Menial job & 28 & 9.2 \\
\hline
\end{tabular}

In table 1, more women (70.9\%) were involved in ICP compared to men (29.1\%) which agrees with $(14,15,8)$ studies but disagree with the findings of $(13,5)$ where the majority of the chicken rearers were males. ICP is independent of age as all categories of age groups were actively involved in the rearing process. $64.1 \%$ of the farmers were married while $23.2 \%$ and $12.7 \%$ were single and widow/divorce respectively. This study has shown that ICP serves as valuable complements to other livelihood options, considering that crop farming (70.9\%) was the primary occupation of the respondents, followed by business (13.7\%), unskilled jobs $(9.2 \%)$ and formal employment $(6.2 \%)$ respectively. Most of the IC farmers have a family size of between 1 and 4 a few $(35.6 \%, 8.8 \%)$ had 58 and 9 plus family size respectively. Education and the required knowledge coupled with managerial training greatly influence the perception, attitude, and behavior of farmers. In this study, more than half of the respondents $(63.1 \%)$ have no formal education while $21.9 \%, 10.8 \%$ and $4.2 \%$ of the respondents have primary, secondary and tertiary education respectively.

Table2. Livestock own, sources, management system, flock composition and method of mating.

\begin{tabular}{|c|c|c|}
\hline Number of livestock own & Frequency & Percentage \\
\hline Indigenous chicken & 2511 & 57 \\
\hline Duck & 377 & 8.6 \\
\hline Goat & 1005 & 22.8 \\
\hline Sheep & 515 & 11.7 \\
\hline \multicolumn{3}{|l|}{ Type of management system } \\
\hline Free-range/extensive & 233 & 76.1 \\
\hline Semi-intensive & 73 & 23.9 \\
\hline \multicolumn{3}{|l|}{ Sources of breeding stock } \\
\hline Purchase & 41 & 13.4 \\
\hline Lending & 119 & 38.9 \\
\hline Exchange & 83 & 27.1 \\
\hline Inherit & 29 & 9.5 \\
\hline Gift & 34 & 11.1 \\
\hline \multicolumn{3}{|l|}{ Flock composition } \\
\hline Hen & 426 & 17 \\
\hline Cock & 219 & 8.7 \\
\hline Chick & 813 & 32.4 \\
\hline Pullet & 503 & 20 \\
\hline Cockerel & 550 & 21.9 \\
\hline \multicolumn{3}{|l|}{ Mating System } \\
\hline Controlled & 0 & 0.0 \\
\hline Uncontrolled & 306 & 100 \\
\hline
\end{tabular}

Farmers interviewed reared different livestock where ICs (57.0\%) and goats (22.8\%) were in the majority (table 2). The main management system reported was the traditional type followed by the semi-intensive system. One or multiple breeds of small-scale chickens (frizzle, naked neck, dwarf, tailless, normal) were reared either separately or together. These breeds possess various phenotypic characteristics such as comb-type, color, shank, beak. Parent stocks were acquired from various sources including lending, purchasing, exchanging, inheriting and gift. Farmers sometimes borrowed parent stock from their close relatives for breeding purposes. Information on the method of selecting showed that parent stocks were selected based on breed types and natural characteristics. It was understood that certain breed categories (straw, dwarf and frizzle hens) have high reproductive potential compared to other breeds (naked neck and normal chickens). However, good plumage color, comb structure, body size, good broody hens, adaptation, resistance to infection, good performance under poor management condition were important characteristics that some respondents observed in selecting parent stock which is in-line with (13) findings. The result of the mating system confirmed 
that all farmers (100\%) observed no controlled mating. Different breeds interact and mate indiscriminately which could distort the rich and diverse indigenous poultry genetic resources and the level of production. The detail flock composition disclosed that out of 2,511 live IC, 32.4\%, 21.9\%, $20.0 \%, 17.0 \%$, and $8.7 \%$ represented chicks, cockerels, pullets, hens, and cocks respectively. The differences in breed composition were linked to diseases, predators, feeding and market demand. Unquestionably, ICP contributes to building and maintaining livelihood, income generation and sociocultural practices in third-world countries including Sierra Leone. The main purpose identified by farmers for rearing ICs was for subsistence use (43.8\%), (table 3).

Table3. Reasons for keeping the indigenous chicken

\begin{tabular}{|l|l|l|}
\hline Reason for rearing IC & Frequency & Percentage \\
\hline Home consumption & 134 & 43.8 \\
\hline Income & 60 & 19.6 \\
\hline Breeding stock & 25 & 8.2 \\
\hline Cultural/religious practices & 87 & 28.4 \\
\hline
\end{tabular}

Religious festivals (Christmas, Easter, Eids) were accomplished with the used of chicken. Income and parent stock were mentioned as additional reasons for rearing ICs (table 3). 19.5\% of the respondents sell live chickens and eggs to address household needs. Income generated was partly used to purchase food items and household utensils, especially in the wet season when farmers experience food shortage. Besides, farmers pay medical bills, school fees, purchase dress, buy planting materials and hire farm labor which is consistent with (16) report where chickens were sold to buy food materials, pay school fees or adjust their flock size. Another important point mentioned for keeping local chicken is the production of high-quality manure which can be used for vegetable production or sold to vegetable producers.

Table4. Household duties performed by men, women, and children in percentages (\%)

\begin{tabular}{|l|l|l|l|l|l|l|}
\hline Duties & Men & \% & Women & \% & Children & \% \\
\hline Provision of chicken shelter & 199 & 65 & 21 & 6.7 & 83 & 27.1 \\
\hline Provision of feed & 59 & 19.3 & 231 & 75.5 & 17 & 5.6 \\
\hline Feeding of chicken & 22 & 7.2 & 93 & 30.4 & 191 & 62.4 \\
\hline Watering of chicken & 34 & 11.1 & 100 & 32.7 & 172 & 56.2 \\
\hline Confinement of chicken & 11 & 3.6 & 27 & 8.8 & 269 & 87.9 \\
\hline Selection of breeding stock & 45 & 14.7 & 243 & 79.4 & 15 & 4.9 \\
\hline Treatment of sick birds & 27 & 8.8 & 263 & 85.9 & 16 & 5.2 \\
\hline Determine bird sales & 184 & 60.1 & 113 & 36.9 & 9 & 2.9 \\
\hline Selling of birds & 69 & 22.5 & 201 & 65.7 & 36 & 11.8 \\
\hline Income controller & 253 & 82.7 & 53 & 17.3 & 0 & 0 \\
\hline Keeping of record & 54 & 17.6 & 95 & 31 & 157 & 51.3 \\
\hline
\end{tabular}

Table 4 presents the various management practices and how they are being accomplished within the household. Women and children accomplish most of the management practices (provision of feed and feeding, watering, confinement, treatment, selection of breeding stock and counting the number of chickens which is similar to (17) report. Children, on the other hand, have been reported with the highest responsibility in housing and releasing the chickens (18). Men, however, were responsible for the provision of shelter; determine when and quantity to sell, and control income earned from the sales of chickens.

Table 5 depicts constraints affecting ICP in the study areas. Diseases/parasites, high mortality, lack of treatment services and information,

Table5. Constraints reported in rearing ICs

\begin{tabular}{|l|l|l|}
\hline Constraints & Frequency & Percentage \\
\hline Diseases and parasites & 302 & 98.7 \\
\hline Lack of treatment & 297 & 97.1 \\
\hline Predators & 231 & 75.5 \\
\hline Theft & 100 & 32.8 \\
\hline Lack of housing & 211 & 68.9 \\
\hline No improved breed & 197 & 64.4 \\
\hline No feeding & 223 & 72.9 \\
\hline
\end{tabular}


Current Status of Indigenous Chicken Production in Moyamba District, Sierra Leone.

\begin{tabular}{|l|l|l|}
\hline Poor marketing system & 67 & 21.9 \\
\hline No information on poultry keeping & 277 & 90.6 \\
\hline High mortality rate & 299 & 97.7 \\
\hline Lack of loan & 53 & 17.3 \\
\hline
\end{tabular}

predators and inadequate housing were ranked as the major constraints while feed shortage, lack of improved breed, theft, lack of market facility and access to credit facility were considered minor constraints. Poor breed quality, limited extension service neighbour conflict, lack of knowledge, proper breed selection and low out were additional constraints. Newcastle disease and predators were reported as a serious threat affecting poultry farmers which agrees with $(19,20)$ findings. Table 6 depicts various diseases identified by farmers. Newcastle Disease (93.8\%), respiratory infections (87.9\%) and fowl pox (75.5\%) were ranked first among others. Newcastle Disease (ND) locally called "Kpekpei" was the most important socio-economic disease characterized by frequent and unpredictable mortality and morbidity particularly in April to June. This is in line with the findings of $(21,22,3)$ who reported ND as a major infectious and economically important disease for rural chicken production resulting in a $100 \%$ mortality and morbidity rate. The disease is well recognized by the farmers by its apparent clinical signs [white greenish diarrhea, nervous problem (twisted neck, paralysis of the wings and legs), high death rate, ruffled feather, respiratory conditions like sneezing and coughing].

Table6. Common diseases and parasites listed by farmers

\begin{tabular}{|l|l|l|}
\hline Table6. Common diseases and parasites listed by farmers & Percentage \\
\hline Diseases & Frequency & 93.8 \\
\hline NCD & 287 & 75.5 \\
\hline Fowl Pox & 231 & 41.2 \\
\hline Fowl diarrhea & 126 & 87.9 \\
\hline Respiratory diseases & 269 & 29.4 \\
\hline Coccidiosis & 90 & 6.9 \\
\hline Infectious bronchitis & 21 & 78.8 \\
\hline Mites & 241 & 9.5 \\
\hline Fleas & 29 & 63.1 \\
\hline Lice & 193 & 23.5 \\
\hline Tick & 72 & 44.5 \\
\hline Worm & 137 & \\
\hline
\end{tabular}

ND affects all breeds of chickens but chicks and broody hens were most susceptible probably due to low immune status and poor management practices which agrees with (21) finding where layers and broody hens were most affected. Due to poor biosecurity measures and carcass management, no separation between sick and healthy chickens and abandoning of infected chickens, diseases were difficult to control. Other diseases mentioned by the farmers include fowl diarrhea (41.2\%), coccidiosis (29.4\%) and infectious bronchitis (6.9\%).

In addition, parasites were also a challenge, especially during the raining season. According to (23), parasitic infestation results not only into death but further causes low production rate and vectors borne diseases (fowl pox, ND). Mites (78.8\%), lice (63.1\%) and worm (44.1\%) were commonly observed compared to fleas and ticks among the poultry population (see table 6). Anaemia, prolong maturity, poor feed utilization, drop in production, and irritation, were apparent clinical conditions described by farmers which are in agreement with $(23,24)$ reports. Chart 1 illustrates the different approaches farmers used when there is an outbreak of parasitic infestation. $90.2 \%$ of the respondents used traditional herbs to control and prevent diseases/parasites while $16.0 \%$ of the farmers agreed to modern treatment type (veterinary services) although this was not an effective service. In severe parasite/disease outbreaks, the majority of the respondents either eat, sell or relocate their chickens. At the start of clinical manifestation, farmers used various traditional medicines to treat symptoms rather than the cause of symptoms. 


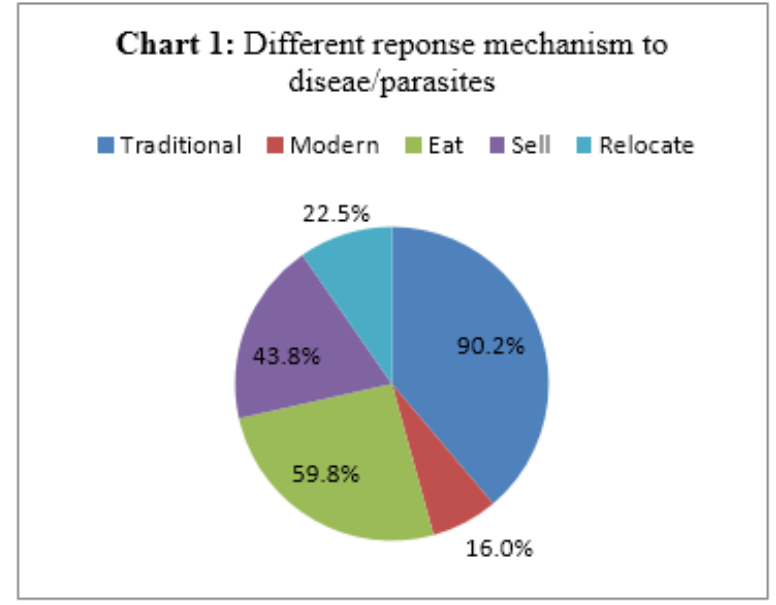

The most frequently used herbs listed include lime, pepper, garlic, and onion. Concoctions of different plants were prepared and administered to all categories of chickens with no recommended dosage. A solution of cigarette filters and tobacco leaves was the most reported treatment for ND in the study areas. The use of Palm oil, salt, and rum - a distilled alcoholic drink (local and imported) was also been reported during outbreaks. Added to this was the wide use of human antibiotic and pills (tetracycline) to treat different infections.

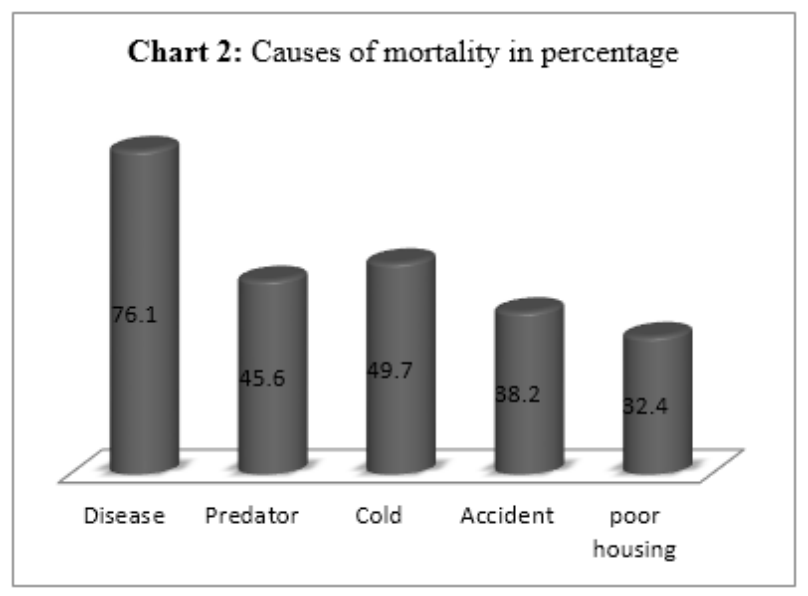

High mortality rate caused by different factors was reported as the second major constraints in the study areas (table 5). In order of severity, diseases, predator, unfavourable weather conditions (heavy rainfall), accident and poor housing were named as major causes of mortality which is in line with $(25,16)$ reports (chart 2). Another challenge recorded was the paucity of information regarding the local poultry industry. Farmers have no access to information on management practices, marketing, and treatment services which is consistent with (26) where lack of information on poultry rearing was mentioned as a challenge due to lack of livestock extension services.

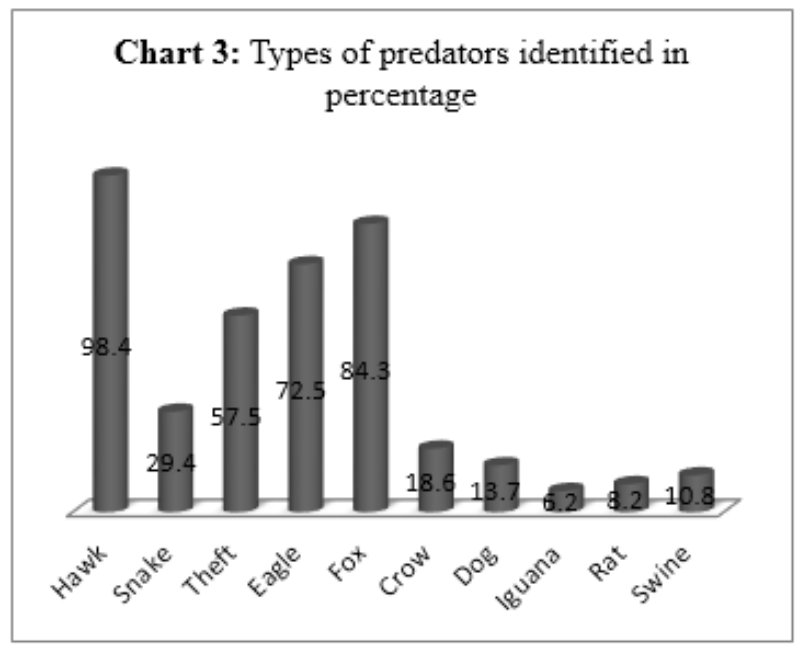


Predators are the most persistent challenge farmers experience in ICP. Predators were major constraints in the free-range system responsible for most premature death and loss of chickens. Some respondents argued that predators caused more death than diseases/parasites which agrees with $(27,28)$ findings where predators were reported as major constraints compared to diseases. In $(29,30)$ studies, predators were listed as the second major constraint. Chart 3 depicts different kinds of predators found in the study areas. Birds of prey (hawk, eagle, crow), reptiles (snake, iguana), wild animals (red fox, rat), dog, swine and man were a serious challenge throughout the year. Hawk (98.4\%), red fox $(84.3 \%)$, eagle $(72.5 \%)$ and man $(57.5 \%)$ were the most destructive predators during the dry season which supports (31) finding where the incidence of predators was highly associated with the dry seasons due to lack of vegetative cover but contradicts (32) finding where the presence of vegetation in the rainy season was the main cause of predation. Dog, swine, rat, and iguana were more common in the raining season. Farmers incur losses ranging from flock reduction, loss of income and cost of production. Dogs and cats are major predators in the extensive management system (33). Different control measures including poison, hunting dogs, stoning (catapult), traps, confinement, and noise were used to kill or scare predators away. In areas where snake incidence was high boiled eggs were used as control measure.

ICs suffer greatly from lack of adequate housing and therefore, they are affected by adverse environmental conditions, theft, predators and improper resting. 9.5\% of those interviewed built shelters for their chickens, $31.1 \%$ did not while 59.4\% shared human dwellings with their chickens. This is in agreement with $(34,35)$ findings where some farmers did not provide shelter and therefore shared dwelling houses with their chickens. Empty bags, fowl coop, metal cage, open-ended drums, carton, and local basket served as a temporal shelter. Chickens slept in trees, verandas, abandoned structures, kitchens, on roofs and the ceilings due to lack of shelters. Stealing, predation, and awareness were the reasons why separate shelters were not provided.

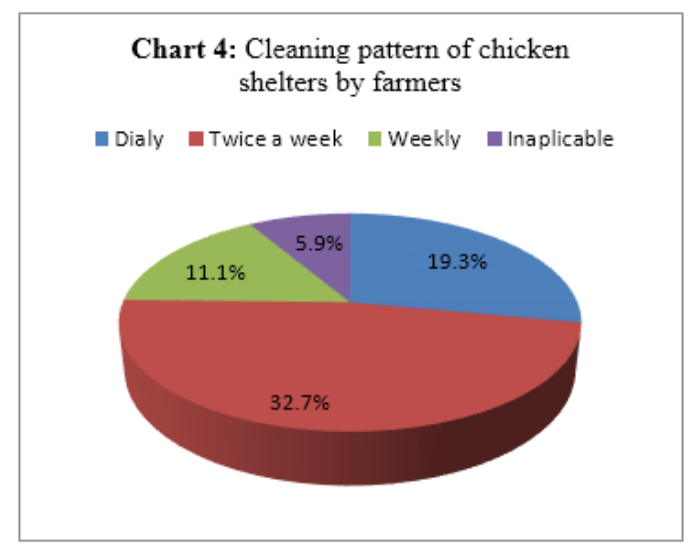

For those with shelters, cleaning and disinfection were very poor lacking respectively. $32.7 \%$ cleaned twice a week, $19.3 \%, 11.1 \%$ cleaned daily and weekly respectively while $5.9 \%$ did not clean. Because good shelter ensures security and health of chickens, extension agents should ensure that farmers are educated on the importance of housing and its contribution to ICP.

ICP in Africa particularly in Sierra Leone is mostly based on scavenging feeding type with little or no supplementation plan. Chickens, therefore, depend on scavenging feeds such as insects, grains, worms, maggots, fruits and other plant materials and less on household remains. $72.9 \%$ of the farmers did not feed their chickens which agrees with (34) finding that stated $88.4 \%$ lack of feeding practices among farmers while $27.1 \%$ provided basic feeding. Grains, maize, rice brown, millet, and wheat were fed during the harvesting period while kitchen wastes, leftover, and processed cassava (Gari) were reportedly supplied throughout the year. The availability of feed greatly depends on the agricultural season and the type of agricultural activities engaged in. Chickens encounter feed scarcity during the raining season because farmers used the available food to feed their families. Added to this was the provision of cleaned drinking water. All the farmers interviewed provide drinking water only in the dry season sometimes before or after feeding. Water from different sources (well, swamp, bore whole, river) was put in permanent containers (wooden, plastic) and placed in open areas (verandas, kitchens, in shades, near houses). Due to the wrong location of water containers, both chickens and other domestic and non-domestic animals drink from the same source which may serve as possible route infection. 
In Sierra Leone, the economic value of indigenous chickens is not directly proportional to the current chicken population reported in the country. This is attributed to the numerous challenges the poultry sector is going through (production, marketing, and technical constraints). 64.4\% of the respondents demanded exotic breeds due to their high product quality. The general performance of local chickens was reportedly low considering the number of their fertility, growth rate, and carcass value.

Marketing of rural chickens was important economic women and children assisted activity which provides the farmers with an immediate source of income all. Although the main production objective is not for marketing, chickens were marketed for household purposes. The market demand for local chickens is high due to their nutritional values. However, this demand supersedes the supply which has left a gap between domestic production and consumption. This gap is partially filled through the importation of packaged meats and eggs from abroad. IC market is poorly understood and it is done informally. Chickens (1-5) per farmer were normally sold at different places [villages, high way, market, town and "Lomour" (local market day)] to different buyers (middlemen, local producers, livestock traders, and eatery) by direct contact which sometimes influenced by season. Several reasons were highlighted why farmers sell their chickens and sometimes eggs. Immediate need of cash, disease outbreak, treatment, and educational purposes, to accomplish religious, cultural, and funeral commitments, payment of local tax, and theft which supports $(36,5,20)$ findings.

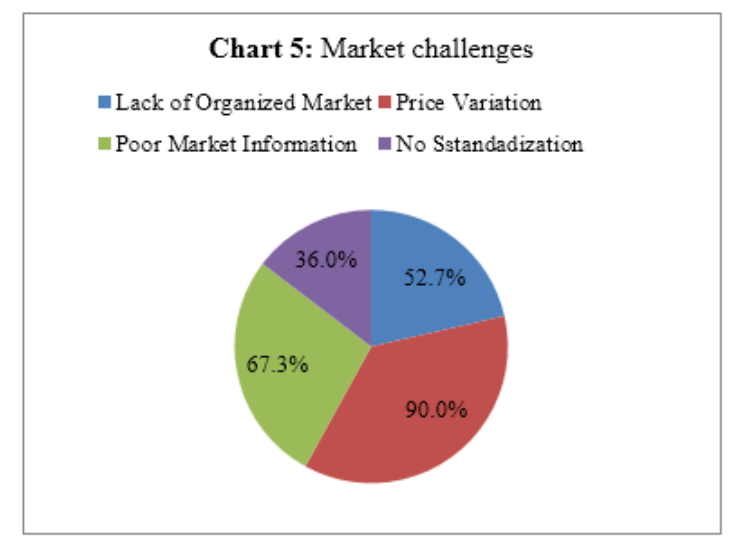

In periods of festivals (religious, social), beginning of school year, or farming season, both demand price increase. Seasonal variation in price is influenced by phenotypic features, market site, breed type, and market information. Poor market information, lack of a well-structured market and standardized system were additional challenges which are in-line with (37) report. Sources of information include traders who determine the cost per chicken (base on weight, age, sex), drivers, and local farmers. This method of transporting chickens to the market is extremely stressful (motorbikes, public transport, hanging by hand) and this has therefore resulted in many deaths, injuries, damage to health and reduction in market value which agrees with (38) finding.

\section{CONCLUSION AND RECOMMENDATION}

In Sierra Leone, rural farmers greatly benefit from ICP by improving their livelihood, promoting socio-cultural values, creating job opportunities and strengthening their economic status. However, the study identified major constraints contributing to the low production of ICs in the study areas. Diseases/parasites; high mortality; lack of treatment and poultry information; predators; lack of feed, housing, and improved breed were identified as major constraints. It is therefore recommended that an immediate and effective intervention be taken to combat the high incidence of disease/parasite, mortality, and predator. This can be achieved by strengthening veterinary services, annual vaccination and training, and community animal health workers. Women should be given basic education on bio-security; adequate feeding, cleaning and provision of shelter to minimize predators' attack, theft, and loss. A well-structured market system in rural areas with access to information will improve and increase the awareness and income level of the farmers.

\section{REFERENCES}

[1] Mack, S., Hoffmann, D. and Otte, J. (2005). The contribution of poultry to rural development. World's Poultry Science Journal 61: 7-14

[2] Hika Waktole, Micheal Almaw, Debella Taweya, Berhane Wakjira, Musie Kiflom, Hagos Ashemafi \& Dinka Ayana, (2018). Opportunities and challenges of indigenous chicken in Asella district, Arsi zone, 
Oromia, Ethiopia: implications for designing improved productivity schemes. Journal of Bacteriology \& Mycology.

[3] D.J. Alexander, J.G., and R.G., Alders, (2004). Technical Review: Newcastle Disease. FAO Animal Production and Health. ISBN 92-5-105080-5

[4] Gueye, (2005). Gender aspects in family poultry management systems in developing countries. World's poultry Science Journal: https://www.researchgate.net.publication/228655443.

[5] Fisseha Moges, AzegeTegegne, Tadelle Dessie, (2010a).Indigenous chicken production and marketing systems in Ethiopia: characteristics and opportunities for market-oriented development. International Livestock Research Institute.

[6] Magothe T.M., Okeno T.O, Muhuyi W.B. \&Kahi A.K. (2012). Indigenouschicken production in Kenya: I. Current status. World's Poultry Science Journal. DOI: 10.1017/50043933912000128

[7] R. Kumar Dutta, M. Saiful Islam and M. Ashraful Kabir, 2013. Production performance of indigenous chicken (Gallus domesticus L.) in some selected areas of Rajshahi, Bangladesh. American Journal of Experimental Agriculture, 3(2): 308-323, www.sciencedomain.org

[8] Ochieng Justus, George Owuor and Bockline Omedo Bebe, (2013). Management practices and challenges in smallholder indigenous chicken production in Western Kenya. Journal of Agriculture and Rural Development in the Tropics and Subtropics, Vol. 114 No. 1(2013) 51-58. ISSN: 1612-9830 www.jarts.info

[9] Sierra Leone food market fundamentals, (2017). Famine Early Warning Systems Networks, USAID.

[10] Population and Housing Census, (2015). Summary of final results, statistics Sierra Leone.

[11] Kate Schneider, Mary Kay Gugerty \& Robert Plotnick, (2010). Poultry Market in West Africa: Sierra Leone. Evans School of Public Affairs, University of Washington

[12] Conteh, A.M. and Gogra, B. (2019). Indigenous pig farming in rural areas of Sierra Leone: Practices, constraints and impact on livelihood. Journal of Animal Science and Veterinary Medicine, Vol. 4(4).

[13] Solomon Zewdu, Binyam Kassa, Bilatu Agza and Ferede Alemu, (2013). Village chicken production systems in Metekel zone, Northwest Ethiopia. Woodpecker Journal of Agricultural Research, Vol. 2 (9), 256-262

[14] Kwaku Agyemang, (2017). Sierra Leone National Livestock Sample Survey. FAO, Sierra Leone.

[15] Hunde Weyuma, Harpal Singh, Mulisa Megersa, (2015). Studies on management practices and constraints of backyard chicken production in selected rural areas of Bishoftu. British Journal of Poultry. ISSN 1995901X. DOI: 10.5829/idosi.bjps.

[16] Bushra Badhaso, (2012). The status of indigenous village chicken production and marketing system in Ethiopia. University of Addis Ababa. DOI: 10.7763/IPEBEE. 2014. V76. 3

[17] Resii, J.C., Permin, A., Vesterlund, C., Ainsh, M.C. and Frederiksen, L. (2004). Keeping village chicken. A technical manual for small-scale poultry production, Copenhagen, Denmark.

[18] Abubakar, M.B., Ambah, A.G. and Tanjdo, T. (2007). Rural chicken production: effect of gender on ownership, and management responsibilities in some parts of Nigeria and Cameroon. International Journal of Poultry Science, 6(6): 413-416.

[19] Aamir Sharif, Muhammad Umer, and Tanveer Ahmed, (2014). Prevention and control of Avian Influenza in poultry production. International Journal of Agriculture Innovations and Research. Volume 2, Issue 6, 2319-1473.

[20] Ahmed Mohammed, (2018). Major constraints and health amangement of village poulty production in Ethiopia. Review school of Veterinary Medicine, Jimma University, Jimma, Ethiopia. International Journal of Research Studies in Microbiology and Biotechnology, 4 (1): 1-10.

[21] Fisseha Moges, Abera Mellesse and Tadelle Dessie, (2010b). Assessment of village chicken production system and the evaluation of the productive and reproductive performance of local chicken ecotype in Bure district, North West Ethiopia. African Journal of Agricultural Research Vol.5 (13), pp 1739-1748. DOI: 10.5897/AJAR09.690. http://www.academicjournals.orh/AJAR.

[22] Serkalem Tadesse, Hagos Ashenefi and Zeleke Aschalew. (2005). Sero-prevalence study of Newcastle disease in local chickens in the central Ethiopia. International Journal of Applied Research Vet. Med. 3(1): 25-29

[23] Nnadi, P.A., and George, S.O. (2010). A cross-sectional survey on parasites of chickens in selected villages in the Subhumid Zones of South-Eastern Nigeria. Journal of Parasitology Research.

[24] Rezaei, F., Hashemnia, M., Chelechale, A., Seidi, S., and Gholizadeh, M. (2016). Prevalence of ectoparasites in free-range backyard chickens, domestic pigeons (Columba livia domestica) and turkeys of Kermanshah province, west of Iran. Journal of Parasitic Diseases, 40(2), 448-453. 
[25] Seth Blackie, (2014). Village chicken production system in the greater Africa region, Ghana. Journal of Biology, Agriculture and Healthcare www.iiste.org. Vol.4, No. 9. ISSN 2224-3208 (Paper) ISSN 2225093X (Online).

[26] Mahoro J, Muasya TK, Mbuza F, Habimana R and Kahi AK, (2017). Characterization of indigenous chicken production systems in Rwanda. Journal of Poultry Science, 2017 Dec 1; 96(12): 4245-4252. DOI: 10.3382/ps/pex240.

[27] Tshering Gyeltshen, Henk M.J. Udo, Fokje Steenstra and Theo Viets, (2012). Characteristics of village chicken production. Why indigenous chickens? Bhu.J.RNR, Vol.8. No. 1, 127-138.

[28] Selam M, Kelay B, (2013). Causes of village chicken mortality and intervention by farmers in Ada'a district, Ethiopia. International Journal of Livestock Production. Vol. 4(6), pp 88.94. DOI: 10.5897/IJLP 12.021. ISSN 2141-2448 @ 2013 Academic Journals. http:/www.academicjournals.org/IJLP

[29] Hunduma Dinka, Regassa Chala, Fufa Dawo, Endale Bekana and Samson Leta, (2010). Major constraints and health management of village poultry production in Rift Valley of Oromia, Ethiopia. Global Veterinarian 5 (1). ISSN 1992-6197.

[30] Shishay Markos, Berhanu Belay and Tadelle Dessie, (2014). Village chicken production constraints and opportunities in Western Zone of Tigray, Northern Ethiopia. Journal of Biology, Agriculture and Healthcare, Vol. No. 27, 2014. www.iiste.org.

[31] Kusina J., Kusina N.T. and Mhlang J. (2004). A survey on village chicken losses: causes and solutions as perceived by farmers.

[32] Sankyan, V., Katoch, S., Thakur, Y.P., Patial, S., and Bhardwaj, N. (2013). Analysis of characteristics and improvement strategies of rural poultry farming in north western Hinewlayan State of Himachal Pradesh, India. Livestock Research for Rural Development.

[33] H. O. Moussa, T.C. Keambou, K. Hima, S. Issa, S. J. Motsa'a, Y. Bakasso, (2018). Indigenous chicken production in Niger. Journal of Veterinary and Animal Science. DOI: 10.1016/J.vas.2018.11.001

[34] T.N. Gondwe \& C.B.A. Wollny, (2017). Local Chicken Production System in Malawi: household flock structure, dynamics, management and health. Tropical animal Health and Production. Volume 39, Issue 2, pp 103-113.

[35] Adelle Dessie and B. Ogli, (2001). Village poultry production systems in the central highland of Ethiopia. Tropical Animal Health and Production, 33 (6) 521-537.

[36] Tabbaa, M.J., Bezabih, E., Berhanu, G. (2000). Small-scale poultry production: Technical guide. FAO, Rome http://www.fao.org/docrep/008/y5169e/y5169e00.htm

[37] Goitom, G., Bezabih E., and Berhanu, G. (2017). Major constraints and opportunities of poultry value chain in Adwa Wereda, Central Zone of Tigray, Ethiopia. Industrial Engineering Letters, ISSN: 2224-6096 (Paper) ISSN: 2225-0582 (Online). Vol. 7, No. 5. www.iiste.org

Citation: Abdulai Mahmood Conteh, "Current Status of Indigenous Chicken Production in Moyamba District, Sierra Leone.", International Journal of Research Studies in Microbiology and Biotechnology (IJRSMB), vol. 5, no. 3, pp. 7-16, 2019. Available: DOI: http://dx.doi.org/ 10.20431/2454-9428.0503003

Copyright: (c) 2019 Authors. This is an open-access article distributed under the terms of the Creative Commons Attribution License, which permits unrestricted use, distribution, and reproduction in any medium, provided the original author and source are credited. 